\title{
Reduced anticoagulation after mechanical aortic valve replacement: Interim results from the Prospective Randomized On-X Valve Anticoagulation Clinical Trial randomized Food and Drug Administration investigational device exemption trial
}

\author{
John Puskas, MD, MSc, FACS, FACC, ${ }^{\mathrm{a}}$ Marc Gerdisch, MD, ${ }^{\mathrm{b}}$ Dennis Nichols, MD, ${ }^{\mathrm{c}}$ Reed Quinn, MD, ${ }^{\mathrm{d}}$ \\ Charles Anderson, MD, ${ }^{\mathrm{c}}$ Birger Rhenman, MD, ${ }^{\mathrm{e}}$ Lilibeth Fermin, MD, ${ }^{\mathrm{e}}$ Michael McGrath, MD, ${ }^{\mathrm{f}}$ \\ Bobby Kong, MD, ${ }^{\mathrm{g}}$ Chad Hughes, MD, ${ }^{\mathrm{h}}$ Gulshan Sethi, MD, ${ }^{\mathrm{i}}$ Michael Wait, MD,${ }^{\mathrm{j}}$ Tomas Martin, MD, ${ }^{\mathrm{k}}$ and \\ Allen Graeve, $\mathrm{MD},{ }^{\mathrm{c}}$ on behalf of all PROACT Investigators
}

\begin{abstract}
Objective: Under Food and Drug Administration investigational device exemption, the Prospective Randomized On-X Anticoagulation Clinical Trial (PROACT) has been testing the safety of less aggressive anticoagulation than recommended by the American College of Cardiology/American Heart Association guidelines after implantation of an approved bileaflet mechanical valve.
\end{abstract}

\begin{abstract}
Methods: In this first limb of the PROACT, patients with elevated risk factors for thromboembolism were randomized at 33 US centers to receive lower dose warfarin (test international normalized ratio [INR], 1.5-2.0) or continue standard warfarin (control INR, 2.0-3.0), 3 months after mechanical aortic valve replacement. The INR was adjusted by home monitoring; all patients received $81 \mathrm{mg}$ aspirin daily. Adverse events were independently adjudicated.
\end{abstract}

Results: A total of 375 aortic valve replacement patients were randomized into control $(n=190)$ and test $(\mathrm{n}=185)$ groups from September 2006 to December 2009. The mean age \pm standard deviation was $55.2 \pm$ 12.5 years; $79 \%$ were men; and $93 \%$ were in sinus rhythm preoperatively. Calcific degeneration was present in $67 \%$; active endocarditis was excluded. Concomitant procedures included coronary artery bypass grafting $(27 \%)$, aortic aneurysm repair (14\%), and other (25\%). The follow-up duration averaged 3.82 years $(755.7$ patient-years [pt-yrs] for control; 675.2 pt-yrs for test). The mean INR was $2.50 \pm 0.63$ for the control and $1.89 \pm 0.49$ for the test groups $(P<.0001)$. The test group experienced significantly lower major $(1.48 \% \mathrm{vs}$ $3.26 \% / \mathrm{pt}-\mathrm{yr} ; P=.047)$ and minor $(1.32 \%$ vs $3.41 \% / \mathrm{pt}-\mathrm{yr} ; P=.021)$ bleeding rates. The incidence of stroke, transient ischemic attack, total neurologic events, and all-cause mortality were similar between the 2 groups.

Conclusions: INR can be safely maintained between 1.5 and 2.0 after aortic valve replacement with this approved bileaflet mechanical prosthesis. With low-dose aspirin, this resulted in a significantly lower risk of bleeding, without a significant increase in thromboembolism. (J Thorac Cardiovasc Surg 2014;147:1202-11)

\section{Supplemental material is available online.}

Earn CME credits at

http://jtcvs.com/cme/home
From the Department of Cardiothoracic Surgery, ${ }^{a}$ Emory University, Atlanta, Ga; Department of Cardiothoracic Surgery, ${ }^{\mathrm{b}}$ Franciscan St Francis Health, Indianapolis, Ind; Department of Cardiothoracic Surgery, ${ }^{\mathrm{c}}$ Multicare Tacoma General, Tacoma, Wash; Department of Cardiothoracic Surgery, ${ }^{\mathrm{d}}$ Maine Medical, Portland, Maine; Department of Cardiothoracic Surgery, ${ }^{\mathrm{e}}$ Southern Arizona Veterans Affairs Hospital, Tucson, Ariz; Department of Cardiothoracic Surgery, ${ }^{\mathrm{f}}$ Sentara Norfolk General Hospital, Norfolk, Va; Department of Cardiothoracic Surgery, ${ }^{g}$ St Joseph Mercy Hospital, Ypsilanti, Mich; Department of Cardiothoracic Surgery, ${ }^{\mathrm{h}}$ Duke University, Durham, NC; Department of Cardiothoracic Surgery, ${ }^{\mathrm{i}}$ University of Arizona, Tucson, Ariz; Department of Cardiothoracic Surgery, ${ }^{j}$ University of Texas, Dallas, Tex; and Department of Cardiothoracic Surgery, ${ }^{\mathrm{k}}$ University of Florida, Gainesville, Fla.

PROACT was sponsored and funded by On-X Life Technologies, Inc (Austin, Tex), the manufacturer of the On-X Prosthetic Heart Valve.

The study was conducted under an investigational device exemption provided by the US Food and Drug Administration.
Despite a long history of success, heart valve replacement therapy has continued to search for the ideal replacement valve. The perfect valve replacement would exhibit a high performance, lack turbulence, be easy and nearly risk free to implant, require no postoperative maintenance, and be impervious to postoperative complications. The present tissue valves fall short of this ideal, because $30 \%$ will

Disclosures: Bobby kong reports equity ownership in and lecture fees from On-X Technologies. Michael McGrath reports equity ownership in Medtronic. Chad Hughes reports consulting and lecture fees from Medtronic, Terumo, and W. L. Gore. All other authors have nothing to disclose with regard to commercial support. See Appendix E1 for a complete listing of all PROACT Investigators.

Read at the 93rd Annual Meeting of The American Association for Thoracic Surgery, Minneapolis, Minnesota, May 4-8, 2013.

Received for publication May 6, 2013; revisions received Dec 27, 2013; accepted for publication Jan 6, 2014; available ahead of print Feb 7, 2014.

Address for reprints: John Puskas, MD, MSc, FACS, FACC, Department of Cardiothoracic Surgery, Emory University Hospital Midtown, 550 Peachtree St, NE, 6th Fl, Medical Office Tower, Atlanta, GA 30308 (E-mail: jpuskas@ emoryedu).

$0022-5223 / \$ 36.00$

Copyright (C) 2014 by The American Association for Thoracic Surgery

http://dx.doi.org/10.1016/j.jtcvs.2014.01.004 


\section{Abbreviations and Acronyms \\ AVR = aortic valve replacement \\ INR = international normalized ratio \\ PROACT $=$ Prospective Randomized On-X \\ Anticoagulation Clinical Trial \\ pt-yrs = patient-years \\ TE $=$ thromboembolism \\ TIA $=$ transient ischemic attack}

structurally fail at 10 to 15 years after implantation. ${ }^{1}$ The present mechanical valves also fall short of this ideal, given the inconvenience of warfarin and the annual risk of bleeding of about $1 \%$ to $2 \%$. $^{2}$ The negative aspects common to both valve types have included perivalvular leak, prosthetic valve endocarditis, pannus, and thromboemboli. These can result in reoperation, stroke, or death; however, they are rare and appear to affect both valve categories equivalently. ${ }^{3}$ Thus, the choice between valve types narrows to one of avoidance of the risk, pain, and costs of reoperation for valve obsolescence versus avoidance of the lifetime composite risk of bleeding and thromboembolism (TE) and the nuisance of ongoing anticoagulation management.

The On- $\mathrm{X}$ valve is a Food and Drug Administration (FDA)-approved, bileaflet mechanical valve designed to function with less anticoagulation, or in some cases, antiplatelet therapy only. Conducted under an FDA investigational device exemption, the Prospective Randomized On-X Anticoagulation Clinical Trial (PROACT) was designed to test whether it is safe and effective to treat patients with less aggressive anticoagulant therapy than currently recommend by the American College of Cardiology/American Heart Association ${ }^{4}$ or American College of Clinical Pharmacy ${ }^{5}$ guidelines after implantation of an approved bileaflet mechanical valve prosthesis. PROACT is composed of 3 separate cohorts. The first cohort to complete enrollment was used to compare standard anticoagulant therapy versus international normalized ratio (INR) goal of 1.5 to 2.0 in high-risk patients requiring aortic valve replacement (AVR). The second will be used to compare current anticoagulant therapy versus aspirin and/or clopidogrel only in selected lower risk patients requiring AVR. The third will be to compare standard anticoagulation therapy versus INR goal of 2 to 2.5 in patients requiring mitral valve replacement. The subject of the present report was the first cohort of patients.

\section{METHODS}

\section{Study Design and Patient Selection}

The high-risk AVR limb of the PROACT study (ClinicalTrials.gov no. NCT00281525) is a prospective, randomized, unblinded, controlled trial comparing the outcomes after AVR with the On- $\mathrm{X}$ valve. It is a multicenter study consisting of 33 centers in North America (see Appendix E1). A total of 425 patients were recruited in the first cohort for AVR in subjects at high risk of TE. Enrollment began after institutional review board approval at each enrolling site in June 2006 and was closed for the high-risk AVR group in October 2009. Interim follow-up data through March 1, 2013 were available for the present report. The primary endpoints were the rates of TE, thrombosis and bleeding, and all-cause mortality, as defined by the Society of Thoracic Surgeons/American Association for Thoracic Surgery guidelines for valve studies. ${ }^{6}$ Noninferiority between the 2 groups was determined using the composite $\mathrm{TE}$, thrombosis and bleeding rate, and a noninferiority margin of $1.5 \%$ (absolute). The sample size estimation was determined using a 1 -sided proportion test with a type 1 error of 0.05 and power of $80 \%$ to test the noninferiority hypothesis.

\section{Patient Inclusion Criteria}

The patient inclusion criteria were as follows:

1. Patients with a clinical indication for isolated AVR

2. Patients with the following conditions, which place a patient in the "high-risk" group: chronic atrial fibrillation, left ventricular ejection fraction $<30 \%$, enlarged left atrium $>50 \mathrm{~mm}$ in diameter, spontaneous echocardiographic contrasts in the left atrium, vascular pathologic features, neurologic events, hypercoagulability, left or right ventricular aneurysm, lack of a platelet response to aspirin or clopidogrel, and women receiving estrogen replacement therapy

3. Concomitant cardiac surgery, including coronary artery bypass grafting, mitral or tricuspid valve repair, ascending aortic replacement, maze procedure, and so forth, were allowed

4. Adult patients (age, $\geq 18$ years)

\section{Patient Exclusion Criteria}

The patient exclusion criteria were as follows:

1. Right-sided valve replacement

2. Double (aortic plus mitral) valve replacement

3. Patients with active endocarditis at implantation

Hypercoagulability in the AVR patients was defined by the following blood tests done preoperatively and before the initiation of warfarin therapy: activated protein $\mathrm{C}$ resistance (factor $\mathrm{V}$-Leiden mutation), prothrombin mutation, antithrombin III activity, protein $\mathrm{C}$ activity, protein $\mathrm{S}$ activity, factor VIII activity, and low-density lipoprotein. Resistance to aspirin or clopidogrel in AVR patients was defined from clinical laboratory test results: urine 11-dehydro-thromboxane B2 for aspirin and P2Y12 for clopidogrel.

\section{Randomization to Test and Control Groups and Crossover Between Groups}

All patients received routine warfarin with a target INR of 2.0 to 3.0, plus $81 \mathrm{mg}$ aspirin daily for the first 3 postoperative months. At 90 days postoperatively, 1:1 randomization was performed using a standard randomization Mersenne Twister algorithm through an on-line randomization module.

Test group: for the first 3 postoperative months, warfarin at an INR target of 2.0 to 3.0 with aspirin $81 \mathrm{mg} / \mathrm{d}$ was used. After 3 months, the warfarin dose was reduced to an INR target of 1.5 to 2.0 , with 81 $\mathrm{mg} / \mathrm{d}$ of enteric-coated aspirin.

Control group: Postoperatively, warfarin at an INR target of 2.0 to 3.0 with $81 \mathrm{mg} / \mathrm{d}$ aspirin was used throughout the study period.

The trial design decision to delay randomization until postoperative day 90 was determined by the belief that randomization to a less aggressive anticoagulation regimen would be safer if conducted after an initial period of 3 months of conventional anticoagulation, during which the fabric sewing cuff of the mechanical valve prosthesis would have become endothelialized. 
Any patient in the test group who experienced a TE event was crossed over to standard anticoagulation therapy (INR, 2.0-3.0 plus $81 \mathrm{mg} / \mathrm{d}$ aspirin), although such patients remained in the test group by intentionto-treat. The FDA protocol did not allow crossover from the control to the test therapy.

\section{Primary Endpoints}

The primary endpoints mandated by the FDA included major bleeding events, minor bleeding events, total bleeding events, transient ischemic attack (TIA), hemorrhagic stroke, nonhemorrhagic stroke, any neurologic event, peripheral TE, any TE, valve thrombosis, TE and thrombosis, major event (major bleeding, any TE, valve thrombosis), death (cardiac, noncardiac, valve-related, and all-cause).

\section{Secondary Endpoints}

The secondary endpoints included endocarditis, hemolysis, hemolytic anemia, paravalvular leak, structural and nonstructural dysfunction, postoperative New York Heart Association class and echocardiographic hemodynamics.

\section{Follow-up Schedule}

The patients were followed up by in-person visits to the study sites at 3 months, 6 months, and 1 year after surgery and then annually for $\geq 5$ and as much as 8 postoperative years to accrue the necessary 800 patient-years of follow-up mandated by the FDA. During these visits, electrocardiography or echocardiography was performed as required by the protocol and as clinically indicated. All patients maintained with warfarin therapy were followed up using weekly home INR testing through a central telephone or online database. The follow-up period was through March 1, 2013 and was complete in $98 \%$ of patients.

\section{INR Management}

All patients received a home INR monitor at randomization. The INR control was maintained using weekly home testing, with warfarin dose adjustments made by the clinical sites to minimize INR variability and maximize the time in the INR target range. Compliance to home monitoring was determined by the frequency of the tests conducted monthly.

\section{Statistical Analysis}

The descriptive statistics for the numeric measures are reported as the mean \pm standard deviation. Statistical tests were conducted using the 2sample $\mathrm{Z}$ test for the mean values and the chi-square (or Fisher's exact) test for proportions. Early adverse events were those occurring before randomization and were calculated as percentages. Late (postrandomization) linearized adverse event rates in \%/patient-year (pt-yr) were compared using relative risk ratios and the intent-to treat method for all subjects who had received $\geq 1$ dose of the study drug. Kaplan-Meier life table curves were calculated from the point of randomization to the first event and compared using the log-rank test. The analyses were performed using Statistical Analysis Systems statistical software, version 9.2 (SAS Institute, Cary, NC).

\section{RESULTS}

From June 2006 to October 2009, 425 patients were enrolled in the AVR high-risk arm of the PROACT trial. The Consolidated Standards of Reporting Trials (CONSORT) flow diagram is shown in Appendix E2. Of these 425 patients, 185 were randomized after 3 postoperative months to the test group and 190 to the control group. The follow-up period averaged 3.82 years through March
1, 2013 (755.7 pt-yrs for the control group and $675.2 \mathrm{pt}-$ yrs for the test group). The remaining 50 patients were removed from the trial before randomization for the following reasons: death $(n=8)$, adverse event exclusion by protocol $(\mathrm{n}=10)$, different or no surgery performed $(\mathrm{n}=14)$, voluntary withdrawal by patient or physician $(\mathrm{n}=11)$, protocol criterion exclusion $(\mathrm{n}=3)$, explantation $(\mathrm{n}=1)$, and lost to follow-up $(\mathrm{n}=3)$. The mean age at surgery was $55.8 \pm 12.0$ years (range, 22-85) for the control group and $54.1 \pm 13.0$ years (range, 20-83) for the test group $(P=.187)$. In the control and test groups, $81 \%$ and $80 \%$ of the patients were men, respectively $(P=.898)$. The present interim analysis was performed because a widening divergence in the incidence of bleeding events between the 2 groups suggested that a difference was possible and early termination might be appropriate, although this investigational device exemption trial continues, pending the FDA ruling.

Comparisons between the 2 groups for native valve pathologic features, valve lesion, preoperative New York Heart Association classification, clinical risk factors, and abnormal laboratory test results are listed in Table 1. No statistically significant differences were found.

The patients were considered minimally compliant if their frequency of testing was at least twice monthlyapproximately twice as often as conventional INR monitoring in a clinician outpatient office. The patients were considered fully compliant when their frequency of testing was $\geq 3$ times monthly. Ideal home monitoring would have resulted in an average interval between the tests of 7 days. In the present study, the average interval between tests was 9 days in both groups. More than $80 \%$ of the patients were minimally compliant with the home monitoring procedures, $>20 \%$ were ideally compliant, and $96 \%$ of all patients at least attempted to conduct home testing once. Finally, 4\% of patients refused home INR monitoring altogether and were monitored by their local physicians at clinic visits. The mean INR was $1.89 \pm 0.50$ for the test subjects (target, 1.5-2.0) and 2.50 \pm 0.64 for the control subjects (target, 2.0 to 3.0). The difference in the INR test results for the groups was highly significant $(P<.0001)$.

Figure 1 shows the distribution of INR measurements by group, clearly demonstrating the lower INR levels maintained in the test group. The percentage of INR measurements in the target range was $63.6 \%$ for the test group and $69.8 \%$ for the control group. The test group in-range percentage was similar to that of the control group, despite the narrower target range. The mean and median INR were within the target range for both groups. The percentage of readings $>3.0$ or $<1.5$ was $17.6 \%$ in the control and $14.0 \%$ in the test group, respectively. These values were the points at which the observed rates of bleeding or TE events began to increase. Figure 2 displays the bleeding and TE event rates stratified by the INR level at the time 
TABLE 1. Preoperative characteristics of test and control groups

\begin{tabular}{|c|c|c|c|}
\hline \multirow[b]{2}{*}{ Class/test } & \multicolumn{2}{|c|}{ AVR high risk } & \multirow[b]{2}{*}{$P$ valu } \\
\hline & $\begin{array}{c}\text { Test } \\
(\mathbf{n}=\mathbf{1 8 5}) \\
\end{array}$ & $\begin{array}{c}\text { Control } \\
(\mathbf{n}=\mathbf{1 9 0})\end{array}$ & \\
\hline \multicolumn{4}{|l|}{ Valve pathologic findings (etiology) } \\
\hline Rheumatic & $3(2)$ & $3(2)$ & .71 \\
\hline Calcific & $121(65)$ & $130(68)$ & .61 \\
\hline Bicuspid & $69(37)$ & $72(38)$ & .93 \\
\hline Endocarditis & $4(4)$ & $5(3)$ & .81 \\
\hline Degenerative & $31(17)$ & $32(17)$ & .89 \\
\hline Prosthetic valve dysfunction & $8(4)$ & $9(5)$ & .79 \\
\hline Valve lesion & & & .24 \\
\hline Stenosis & $95(52)$ & $97(51)$ & \\
\hline Regurgitation & $46(25)$ & $34(18)$ & \\
\hline Mixed & $39(21)$ & $54(28)$ & \\
\hline NYHA class & & & .44 \\
\hline I & $39(21)$ & $36(19)$ & \\
\hline II & $73(39)$ & $73(38)$ & \\
\hline III & $50(27)$ & $51(27)$ & \\
\hline IV & $7(4)$ & $16(8)$ & \\
\hline Unknown & $16(9)$ & $14(7)$ & \\
\hline \multicolumn{4}{|l|}{ Clinical risk factors } \\
\hline Atrial fibrillation & $3(2)$ & $11(6)$ & .06 \\
\hline Ejection fraction $<30 \%$ & $9(5)$ & $7(4)$ & .75 \\
\hline Estrogen therapy & $4(2)$ & $2(1)$ & .66 \\
\hline Left atrial diameter $>50 \mathrm{~mm}$ & $15(8)$ & $22(12)$ & .34 \\
\hline Neurologic events & $6(3)$ & $9(5)$ & .63 \\
\hline $\begin{array}{l}\text { Spontaneous echocardiographic } \\
\text { contrasts }\end{array}$ & $0(0)$ & $2(1)$ & .46 \\
\hline Ventricular aneurysm & $1(0.5)$ & $1(0.5)$ & .46 \\
\hline \multicolumn{4}{|l|}{ Abnormal laboratory tests } \\
\hline AT-III activity & $28(15)$ & $24(13)$ & .58 \\
\hline Factor VIII activity & $1(0.5)$ & $1(0.5)$ & .46 \\
\hline Factor V Leiden mutation & $5(3)$ & $3(2)$ & .48 \\
\hline Protein $\mathrm{C}$ activity & $9(5)$ & $9(5)$ & .70 \\
\hline Prothrombin mutation & $4(2)$ & $3(2)$ & .96 \\
\hline Protein $S$ activity & $3(2)$ & $3(2)$ & .68 \\
\hline P2Y12 inhibition & $42(23)$ & $52(27)$ & .35 \\
\hline Urine thromboxane & $84(45)$ & $69(36)$ & .09 \\
\hline
\end{tabular}

Data presented as $\mathrm{n}(\%)$. Incidence rates by disease etiology and comparison of test and control groups using a chi-square test of significance (including Yates' correction for continuity for small sample sizes). AVR, Aortic valve replacement; NYHA, New York Heart Association; AT-III, antithrombin III.

of the event using the method of Rosendaal and colleagues. ${ }^{7}$ The best fit curves of the data are also shown, indicating an intersection between the bleeding and TE curves at the INR 1.5 to 2.0 range. These curves also indicated that the incidence of TE increased when the INR decreased to $<1.5$, suggesting 1.5 as the lower boundary of appropriate warfarin anticoagulation in this patient population with preoperative risk factors for TE.

Patients experiencing serious adverse events, including death and TE, before randomization at 3 postoperative months were excluded from randomization and follow-up. The patients who experienced major, minor, and perioperative bleeding were allowed to proceed to randomization at

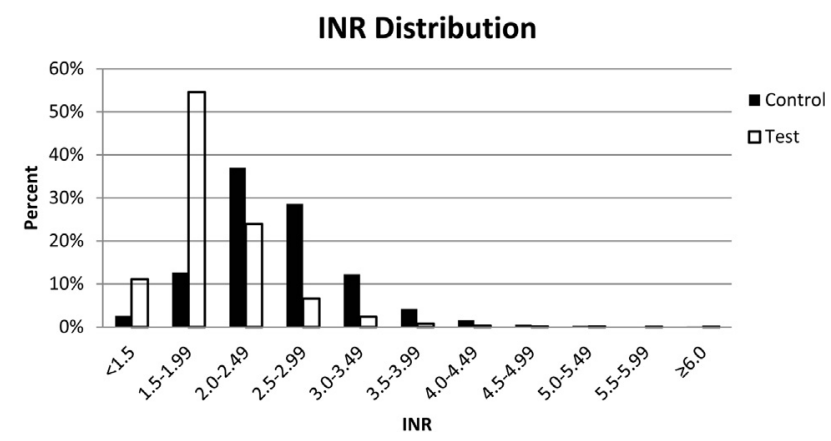

FIGURE 1. International normalized ratio (INR) distributions.

the investigator's judgment; however, most patients who had experienced major bleeding were not randomized. One patient who experienced a minor stroke in the prerandomization period was mistakenly randomized and was immediately withdrawn from the study.

The results of the primary endpoint events are listed in Table 2. Figure 3 provides primary endpoint life tables for overall bleeding and TE, including their 5-year event-free rates. The linearized event rates demonstrated that the test group experienced a significant improvement in both major and minor bleeding, with an overall $62 \%$ reduction in bleeding events. The life tables confirmed this, depicting a bleeding curve for the test group significantly below that for the control group.

Both the linearized and life table analyses found no significant difference in the rates of thrombotic events between the 2 groups. The difference in bleeding events between the 2 groups was large enough to drive the comparison of composite bleeding and TE rates between groups to statistical significance $(P=.046)$, in favor of the test group. No differences were seen in mortality between the 2 groups; the rates of other valve-related events not shown in Table 2 were all $<1 \% / \mathrm{pt}-\mathrm{yr}$ and were similar between the 2 groups.

Before randomization, 4 patients had died within the first 30 days and 4 more between 30 and 90 days. The 4 early deaths were from cardiogenic shock, multiorgan failure, biventricular failure, and atheroembolic shower leading to renal failure; all occurred within 2 days of surgery. The 4 deaths occurring at 30 to 90 postoperative days were from sudden death of unknown cause, prosthetic endocarditis, cerebral hemorrhage, and arrhythmia.

After randomization, the incidence of sudden death was the same in both groups (3 $[0.44 \% / \mathrm{pt}-\mathrm{yr}])$. One cardiac death occurred in the control group due to chronic obstructive pulmonary disease and congestive heart failure. No other late cardiac deaths occurred. Valve-related deaths included cerebral bleeding in the control group and 1 ischemic stroke and 1 cerebral bleeding in the test group. The remaining late deaths were determined by independent adjudication to be noncardiac. In the control group, these included 3 from cancer, 1 from multisystem organ failure, 
INR versus Event Rate

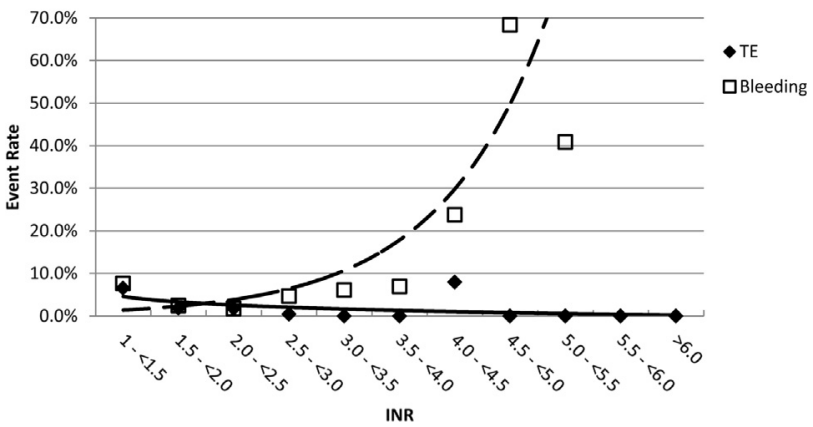

FIGURE 2. Relationship between the international normalized ratio (INR) at the event and the event rates. TE, Thromboembolism.

1 from pancreatitis, and 1 from sepsis. In the test group, noncardiac deaths included 2 from cancer, 1 from cerebral artery disease, 1 from chronic obstructive pulmonary disease with pulmonary embolism, and 1 from traumatic death.

A qualitative evaluation of reoperation and explants revealed that the types and causes of the reoperations and explants were those generally expected after AVR and were similar between the 2 groups. Before randomization, the most common surgical procedure was re-exploration for perioperative bleeding, which occurred 22 times $(5.2 \%$ or about one half of all perioperative bleeding events). New pacemaker insertion within 14 days was the second most common procedure and occurred in 19 patients $(4.5 \%)$. Other early procedures were for gastrointestinal bleeding, prosthetic endocarditis, sternal rewiring, and an occult pregnancy; each occurred once. After randomization, valverelated reoperations were related to prosthetic endocarditis ( 1 control, explanted; 4 test, 3 explanted), paravalvular leak ( 1 control, repaired; 1 test, explanted), thrombosis ( 1 control, explanted; 2 test, 1 explanted), peripheral thrombectomy ( 1 control; 2 test), bleeding ( 1 control; 2 test), and heart transplantation (1 test, explanted). Overall, the rate of postrandomization reoperations was $0.66 \% / \mathrm{pt}-\mathrm{yr}$ for the control group and $1.77 \% / \mathrm{pt}-\mathrm{yr}$ for the test group $(P=.053)$, and the rate of explants was $0.26 \%$ in the control and $0.89 \%$ in the test groups $(P=.115)$. Types and numbers of reoperations and explants are statistically similar between groups.

TIA was defined as a neurologic deficit lasting $\leq 3$ days. Five TIAs occurred in the control group, with an average duration of 1.6 days, and seven in the test group, averaging 1 day in duration. These were all short-duration blindness, numbness, weakness, or tingling in patients whose

TABLE 2. AVR high-risk postrandomization event comparisons

\begin{tabular}{|c|c|c|c|c|c|c|c|}
\hline \multirow[b]{2}{*}{ Primary event } & \multicolumn{2}{|c|}{ Test group $(\mathrm{pt}-\mathrm{yr}=675.2)$} & \multicolumn{2}{|c|}{ Control group $(\mathrm{pt}-\mathrm{yr}=755.7)$} & \multirow[b]{2}{*}{ Rate ratio (test/control) } & \multirow[b]{2}{*}{$95 \%$ CI } & \multirow[b]{2}{*}{$P$ value } \\
\hline & Patients (n) & Rate $(\% /$ pt-yr) & Patients (n) & Rate (\%/pt-yr) & & & \\
\hline \multicolumn{8}{|l|}{ Bleeding } \\
\hline Major & 10 & 1.48 & 25 & 3.31 & 0.45 & $0.21-0.94$ & .032 \\
\hline Hemorrhagic stroke & 1 & 0.15 & 2 & 0.26 & 0.56 & $0.01-10.7$ & .630 \\
\hline Death & 1 & 0.15 & 1 & 0.13 & 1.15 & $0.01-87.8$ & .937 \\
\hline Long-term* & 0 & 0.00 & 1 & 0.13 & NA & NA & NA \\
\hline Short-term $\dagger$ & 0 & 0.00 & 0 & 0.00 & NA & NA & NA \\
\hline Minor & 8 & 1.18 & 25 & 3.31 & 0.36 & $0.16-0.79$ & .011 \\
\hline Total & 18 & 2.67 & 50 & 6.62 & 0.40 & $0.24-0.69$ & $<.001$ \\
\hline Ischemic stroke & 5 & 0.74 & 5 & 0.66 & 1.12 & $0.32-3.87$ & .859 \\
\hline Death & 1 & 0.15 & 0 & 0.00 & NA & NA & NA \\
\hline Long-term* & 1 & 0.15 & 2 & 0.26 & 0.56 & $0.01-10.7$ & .630 \\
\hline Short-term $\dagger$ & 3 & 0.44 & 3 & 0.40 & 1.12 & $0.15-8.35$ & .891 \\
\hline TIA & 9 & 1.33 & 6 & 0.79 & 1.68 & $0.60-4.72$ & .326 \\
\hline Neurologic event & 14 & 2.07 & 11 & 1.46 & 1.42 & $0.65-3.14$ & .380 \\
\hline Peripheral TE & 4 & 0.59 & 1 & 0.13 & 4.48 & $0.50-40.06$ & .180 \\
\hline All TE & 18 & 2.67 & 12 & 1.59 & 1.68 & $0.81-3.49$ & .164 \\
\hline Thrombosis & 2 & 0.30 & 2 & 0.26 & 1.12 & $0.16-7.95$ & .910 \\
\hline TE and thrombosis & 20 & 2.96 & 14 & 1.85 & 1.60 & $0.81-3.17$ & .178 \\
\hline $\begin{array}{l}\text { Major event (major bleeding, } \\
\text { all TE, thrombosis) }\end{array}$ & 30 & 4.44 & 39 & 5.16 & 0.86 & $0.54-1.40$ & .539 \\
\hline All above events & 38 & 5.63 & 64 & 8.47 & 0.66 & $0.44-0.99$ & .046 \\
\hline Sudden death & 3 & 0.44 & 3 & 0.40 & 1.12 & $0.23-5.55$ & .890 \\
\hline $\begin{array}{l}\text { Valve-related death (without } \\
\text { sudden) }\end{array}$ & 2 & 0.30 & 1 & 0.13 & 2.24 & $0.20-24.69$ & .511 \\
\hline Cardiac death & 0 & 0.00 & 1 & 0.13 & NA & NA & NA \\
\hline Noncardiac death & 5 & 0.74 & 6 & 0.79 & 0.93 & $0.23-3.67$ & .908 \\
\hline Total mortality & 10 & 1.48 & 11 & 1.46 & 1.02 & $0.43-2.40$ & .968 \\
\hline
\end{tabular}

pt-yr, Patient-year; $C I$, confidence interval; NA, not applicable; TIA, transient ischemic attack; TE, thromboembolism. *More than 3 days. $\dagger$ Within 3 days or less. 

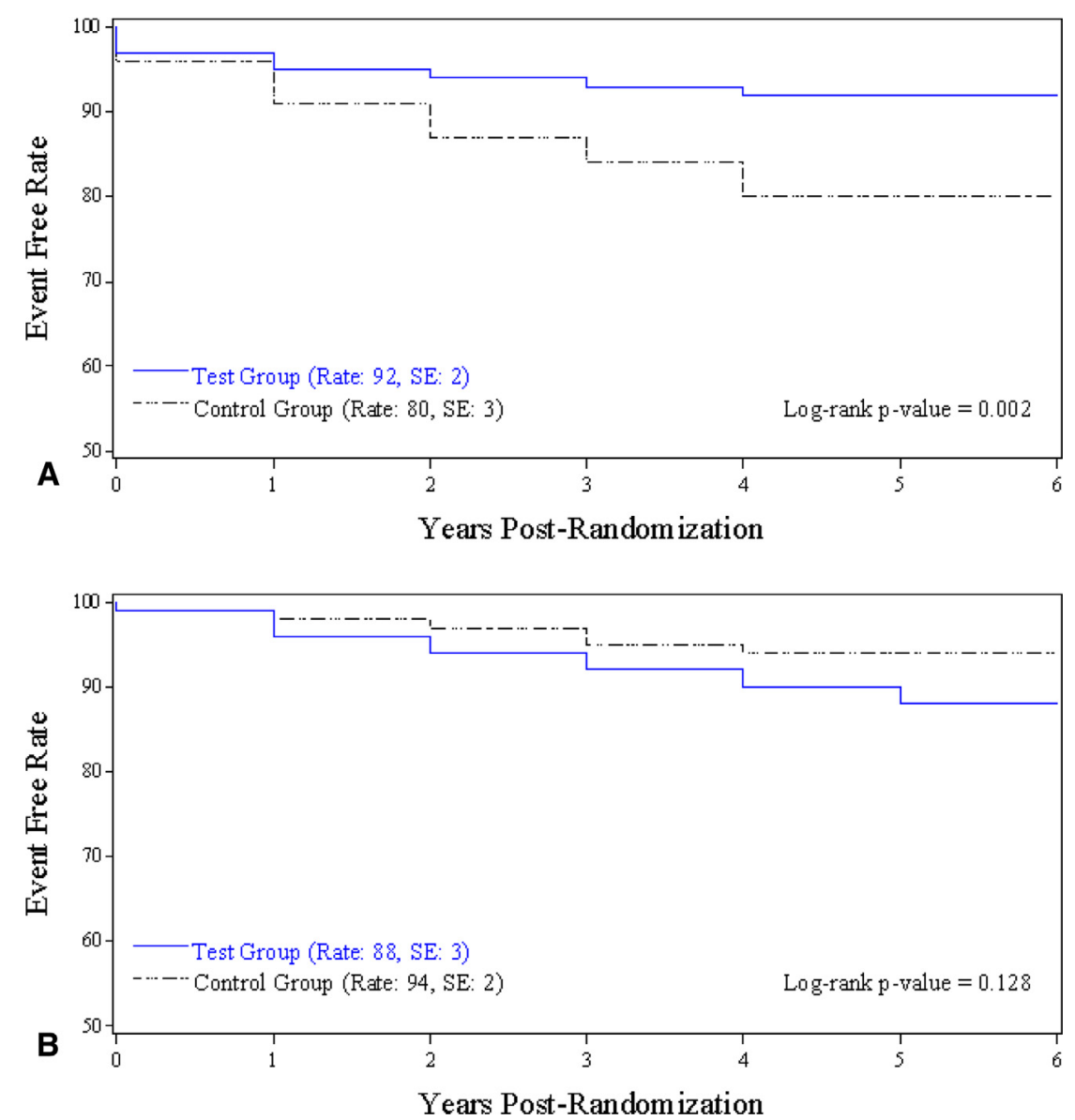

FIGURE 3. Kaplan-Meier life tables with 5-year event-free rates. A, Kaplan-Meier plot of major or minor bleeding events. B, Kaplan-Meier plot of thromboembolism. SE, Standard error.

computed tomography or magnetic resonance imaging scans showed no circulation abnormality or new cerebral infarction. Five ischemic strokes each occurred in the control and test groups. Of these, 3 each in the control and test groups had resolved within 3 days but the computed tomography and magnetic resonance imaging results were positive. Two control patients and 1 test patient experienced a permanent neurologic deficit, and 1 test patient died of stroke on the second postoperative day. No significant difference was found in the incidence of neurologic events between the 2 groups as shown in Table 2.

A review of the PROACT database with $>53,000$ INR measurements revealed that the level of anticoagulation at the TE event was worthy of attention. TEs did not consistently occur if the INR was below the target range in either group. Overall, the percentage of TE events that occurred with the patient within the INR target range was $67 \%$ (6 of 9 ) in the control group and $53 \%$ (8 of 15) in the test group $(P=.806)$. In each group, 1 patient was greater than the INR target range at the occurrence of the TE event. However, $22 \%$ ( 2 of 9 ) were at less than the target range in the control group and $40 \%$ (6 of 15) were at less than the INR target range in the test group $(P=.646)$ at TE. These data suggest that an INR of 1.5 might be the bottom of the appropriate range of anticoagulation for high-risk AVR patients.

Valve thrombosis was qualitatively different from TE in that all 4 valve thrombosis events occurred in patients who had stopped taking warfarin against medical advice. These cases were managed by valve explantation ( 1 control and 1 test), 1 thrombectomy, and 1 spontaneous resolution with the re-administration of warfarin. All 4 patients recovered.

Of the primary endpoint events, 35 were major bleeding events, 34 minor, 10 strokes, and 15 were TIAs. Major bleeding events were further classified into 5 cerebral events, 27 gastrointestinal, 3 hematomas, and 2 nosebleeds. All these patients, except for those with cerebral bleeding events, had recovered after a median of 8 days. Cerebral bleeding events resulted in 2 deaths and 1 permanent deficit. The patients who experienced TIAs all recovered without treatment within $<3$ days. Nonhemorrhagic strokes resulted 
in 1 death $(10 \%)$ and 3 permanent deficits; 5 patients recovered fully within $<3$ days. These were only classed as cerebrovascular accidents because the computed tomography or magnetic resonance imaging scans found a clot. The clinical implications of hemorrhagic cerebral events were much more severe than the consequences of nonhemorrhagic strokes in this limb of the PROACT study. A summary of all cerebrovascular events by group has been included in Table 2.

The distribution of valve sizes in the high risk limb of the PROACT trial mirrored common practice in mechanical aortic valve replacement, with 45 of 425 valves size 19 $\mathrm{mm}, 122$, size $21 \mathrm{~mm}, 145$, size $23 \mathrm{~mm}, 61$, size $25 \mathrm{~mm}$, and 39 valves size $27 / 29 \mathrm{~mm}$. No significant differences were found in the relative risk of TE or hemorrhagic events between the test and control groups across the different valve sizes.

\section{DISCUSSION}

In 1995, Cannegieter and colleagues ${ }^{8}$ published an indepth analysis of anticoagulation and adverse events in early model mechanical valves. The development of a normalized method of evaluating the anticoagulant status through the INR for prothrombin time allowed the comparison of event rates across a large number of patients according to their anticoagulation level. Cannegieter and colleagues $^{8}$ defined an optimum range for INR to minimize thrombotic and hemorrhagic complications. Thrombotic events occurred more frequently as the INR decreases and hemorrhagic events have been more common as the INR increases; thus, the zone at which the 2 event curves intersect defines the optimum therapeutic INR. The recommendations for the proper level of anticoagulation for heart valves of various types and under various circumstances have ranged over the years from 2.0 to 4.5 . At present, the accepted range for a bileaflet mechanical valve in the aortic position is 2.0 to 3.0 and in the mitral position is 2.5 to $3.5^{4,5}$

Horstkotte and colleagues ${ }^{9}$ and Cannegieter and colleagues ${ }^{8}$ recognized that the bleeding event curve is essentially independent of the valve type, being more directly related to patient factors and the level of anticoagulation, and can be considered a constant curve. The thrombotic event curve, however, is the result of a more complicated mix of factors, including patient factors, valve factors, and the anticoagulation level. It is reasonable to speculate that if every valve were examined by these methods, a family of curves would result. If the patient factors were held constant by careful patient selection, the resulting family of curves would represent the relative thrombogenicity of each valve, with the more resistant valves toward the left. The optimum INR range for the more thromboresistant valve would be lower and the end result would be fewer complications (combined TE and bleeding events) for patients with that valve. Butchart, ${ }^{10}$ in a review of embolism in prosthetic heart valves, concluded that valves vary in susceptibility to thrombosis owing to subtle design differences, that the optimal INR range is often uncertain, and that additional research is needed.

Many studies of various mechanical valves have examined low-intensity warfarin therapy, warfarin plus aspirin, aspirin alone, and, even, no anticoagulation. These studies have had mixed results. Horstkotte and colleagues ${ }^{9}$ suggested that INR levels of 3.0 to 4.5 were too high for the St Jude valve; however, a prospective trial is needed to determine the optimal level. Cannegieter and colleagues, ${ }^{8}$ in the first detailed study of optimum anticoagulation, suggested a target INR of 3.0 to 4.5 . More recently, Torella and colleagues ${ }^{11}$ reported a successful randomized trial in lowrisk mechanical AVR patients in whom the INR was maintained at 1.5 to 2.5 . Bleeding was significantly reduced in the test group and the TE rates were noninferior. ${ }^{11}$ Others have suggested lower INR targets in the range of 2.0 to 3.0. ${ }^{9,12,13}$ These studies resulted in the present recommendations of American College of Clinical Pharmacy $^{5}$ and American Heart Association/American College of Cardiology. ${ }^{4}$

Turpie and colleagues ${ }^{14}$ and other groups ${ }^{15,16}$ have reported the benefit of adding aspirin or dipyridamole to warfarin therapy. Others have suggested a possible increase in the risk of bleeding with the addition of aspirin. ${ }^{17} \mathrm{~A}$ meta-analysis ${ }^{18}$ supported the addition of low-dose aspirin or dipyridamole to warfarin for patients with mechanical cardiac valve prostheses.

Another strategy to reduce the TE and bleeding events associated with warfarin therapy has been to more closely manage anticoagulation therapy with frequent clinic or home monitoring of INR. These studies have uniformly shown better clinical outcomes with better control. ${ }^{19-21}$ The low overall rates of adverse hemorrhagic and thromboembolic events observed in the PROACT trial might have been due, in part, to the uniform use of home INR monitoring and the high degree of compliance among the enrolled patients.

Several investigations have explored the thrombogenicity of the On-X bileaflet mechanical valve. In 1996, the first clinical trial of the On-X valve to establish its safety and effectiveness began in Europe and included 184 AVR patients. The final report of the study was completed in 2004 with a minimum of 5 years of follow-up per patient. This report was published by Palatianos and colleagues, ${ }^{22}$ with a late TE rate of $0.88 \% / \mathrm{pt}-\mathrm{yr}$ and bleeding rate of $0.77 \% / \mathrm{pt}$-yr. Chambers and colleagues ${ }^{24}$ published a 12 -year experience with a $0.6 \% / \mathrm{pt}$-yr TE rate for AVR patients combined with a $0.4 \% / \mathrm{pt}-\mathrm{yr}$ major bleeding rate. The patients in the present trial were monitored clinically with an INR target of 2 to 3 . In an ongoing clinical trial in South Africa, ${ }^{23} 104$ On-X AVR valves were implanted, 
with $95 \%$ follow-up data $\leq 4.8$ years. Although $40 \%$ of these patients were not receiving anticoagulation therapy because of the social conditions in South Africa, no AVR thromboses were reported in their study. ${ }^{23}$ The late TE rate was $1.1 \% / \mathrm{pt}-\mathrm{yr}$, and the bleeding rate was $0.6 \% / \mathrm{pt}-$ yr. Low TE rates with the On-X valve might be attributable to several design features, including its manufacture from pure pyrolytic carbon, ${ }^{25}$ a flared inlet, increased height to cylinder ratio, $180^{\circ}$ leaflet opening, and increased "washing" of potentially thrombogenic hinge points.

A total of 14 patients (3.7\% of the total) had preoperative atrial fibrillation. Three of these were randomized to the test group and were treated with an INR of 1.5 to 2.0 and aspirin $81 \mathrm{mg} / \mathrm{d}$. This FDA-sanctioned protocol treated some of these patients with slightly less aggressive anticoagulation than present guidelines would recommend. However, no TE or hemorrhagic events occurred in any of these 14 patients.

In the present PROACT study, high-risk AVR patients randomized after 3 postoperative months of standard anticoagulation to receive reduced warfarin therapy (INR, 1.5-2.0) with aspirin $81 \mathrm{mg} / \mathrm{d}$ experienced a lower incidence of bleeding complications and a similar incidence of thrombotic complications compared with those who continued standard anticoagulation. TE events were more common when the INR had decreased to $<1.5$. Bleeding events were more common in the test and control groups both when the INR had increased to greater than the target range. Compliance with home INR monitoring was associated with tight INR control and fewer TE and bleeding complications.

\section{Study Limitations}

The PROACT study had numerous limitations. Perhaps, most importantly, all patients reported in the present study underwent AVR with a single, approved, bileaflet mechanical valve prosthesis. The results from the present trial should not be extrapolated to other prostheses, mechanical mitral valve replacements, or patients undergoing double AVR/mitral valve replacement. The present standard of care for all mechanical AVR patients outside the PROACT study remains conventional anticoagulation, as indicated by the American Heart Association/American College of Cardiology guidelines. ${ }^{4}$

Although the high-risk AVR limb of the PROACT demonstrated that a target INR range of 1.5 to 2.0 combined with low-dose aspirin therapy can be safe and efficacious, this does not imply that an INR value at either end of the range is of equal benefit. TE events were more common in high-risk AVR patients when the INR decreased to $<1.5$.

The sample size of PROACT was not designed to determine whether less aggressive anticoagulation therapy is safe for different sizes of On-X AVR prostheses, although the data obtained did not indicate a predisposition toward more adverse events with larger or smaller valve sizes.

\section{CONCLUSIONS}

INR can be safely maintained at 1.5 to 2.0 in high-risk AVR patients after implantation of this approved bileaflet mechanical prosthesis. Combined with low-dose aspirin, this therapy resulted in a significantly lower risk of bleeding than the customary INR range of 2.0 to 3.0, without a significant increase in TE events. To maximize the safety and effectiveness of this therapeutic change in high-risk AVR recipients of On-X valves, the INR should be assiduously kept $>1.5$.

\section{References}

1. Smedira NG, Blackstone EH, Roselli EE, Laffey CC, Cosgrove DM. Are allografts the biologic valve of choice for aortic valve replacement in nonelderly patients? Comparison of explantation for structural valve deterioration of allograft and pericardial prostheses. J Thorac Cardiovasc Surg. 2006;131:558-64.

2. Akins C. Results with mechanical cardiac valvular prostheses. Ann Thorac Surg. 1995;60:1836-44.

3. Khan S, Trento A, DeRobertis M, Kass RM, Sandhu M, Czer LS, et al. Twentyyear comparison of tissue and mechanical valve replacement. J Thorac Cardiovasc Surg. 2001;122:257-69.

4. Bonow RO, Carabello BA, Chatterjee K, de Leon AC Jr, Faxon DP, Freed MD, et al. 2008 Focused update incorporated into the ACC/AHA 2006 guidelines for the management of patients with valvular heart disease: a report of the American College of Cardiology/American Heart Association Task Force on Practice Guidelines (Writing Committee to Revise the 1998 Guidelines for the Management of Patients With Valvular Heart Disease): endorsed by the Society of Cardiovascular Anesthesiologists, Society for Cardiovascular Angiography and Interventions, and Society of Thoracic Surgeons. Circulation. 2008;118:e523-661.

5. Stein PD, Alpert JS, Bussey HI, Dalen JE, Turpie AG. Antithrombotic therapy in patients with mechanical and biological prosthetic heart valves. Chest. 2001;119: 220S-7S.

6. Akins CW, Miller DC, Turina MI, Kouchoukos NT, Blackstone EH, Grunkemeier GL, et al. Guidelines for reporting mortality and morbidity after cardiac valve interventions. J Thorac Cardiovasc Surg. 2008;135:732-8.

7. Rosendaal FR, Cannegieter SC, van der Meer FJM, Briet E. A method to determine the optimal intensity of oral anticoagulant therapy. Thromb Haemost. 1993; 69:236-9.

8. Cannegieter SC, Rosendaal FR, Wintzen AR, van der Meer FJM, Vandenbroucke JP, Briet E. Optimal oral anticoagulant therapy in patients with mechanical heart valves. N Engl J Med. 1995;333:11-7.

9. Horstkotte D, Schulte HD, Bircks W, Strauer BE. Lower intensity anticoagulation therapy results in lower complication rates with the St. Jude Medical prosthesis. J Thorac Cardiovasc Surg. 1994;107:1136-45.

10. Butchart EG. Prosthetic heart valves. In: Verstraete M, Fuster V, Topol EJ, eds Cardiovascular Thrombosis: Thrombocardiology and Thromboneurology. 2nd ed. Philadelphia: Lippincott-Raven; 1998:395-413.

11. Torella M, Torella D, Chiodini P, Franciulli M, Romano G, De Santo L, et al Lowering the intensity of oral anticoagulant therapy in patients with bileaflet mechanical aortic valve replacement: results from the LOWERING-IT trial. Am Heart J. 2010;160:171-8.

12. Anderson PV, Aagaard J. Low-dose warfarin in patients with Carbomedics heart valve prostheses. Asian Cardiovasc Thorac Ann. 2000;8:11-4.

13. Acar J, Iung B, Boissel JP, Samama MM, Michel PL, Teppe JP, et al. AREVA: multicenter randomized comparison of low-dose versus standard-dose anticoagulation in patients with mechanical prosthetic heart valves. Circulation. 1996; 94:2107-12.

14. Turpie AGG, Gent M, Laupagcis A, Latour Y, Gunstensen J, Basile F, et al. A comparison of aspirin with placebo in patients treated with warfarin after heart-valve replacement. N Engl J Med. 1993;329:524-9.

15. Skudicky D, Essop MR, Wisenbaugh T, Skoularigis J, Essop AR, Dullabh A, et al. Frequency of prosthetic valve-related complications with very low level warfarin anticoagulation combined with dipyridamole after valve replacement using St. Jude Medical prostheses. Am J Cardiol. 1994;74:1137-41.

16. Yamak B, Iscan Z, Mavitas B, Ulus AT, Katricioglu SF, Tasdemir O, et al. Lowdose oral anticoagulation and antiplatelet therapy with St. Jude Medical Heart Valve prosthesis. J Heart Valve Dis. 1999;8:665-73. 
17. Altman R, Rouvier J, Gurfinkel E, Scazziota A, Turpie AGG. Comparison of high-dose with low-dose aspirin in patients with mechanical heart valve replacement treated with oral anticoagulant. Circulation. 1996;94:2113-6.

18. Cappelleri JC, Fiore LD, Brophy MT, Deykin D, Lau J. Efficacy and safety of combined anticoagulant and antiplatelet therapy versus anticoagulant monotherapy after mechanical heart-valve replacement: a meta-analysis. Am Heart J. 1995; 130:547-52.

19. Körtke H, Körfer R. International normalized ratio self-management after me chanical heart valve replacement: is an early start advantageous? Ann Thorac Surg. 2001:72:44-8.

20. Butchart EG, Payne N, Li HH, Buchan K, Mandana K, Grunkemeier GL. Better anticoagulation control improves survival after valve replacement. J Thorac Cardiovasc Surg. 2002;123:715-23.

21. Bamford J, Warlow CP. Stroke and TIA in the general population. In: Butchart EG, Bodnar E, eds. Current Issues in Heart Valve Disease: Thrombosis, Embolism and Bleeding. London: ICR; 1992:3-15.

22. Palatianos G, Laczkovics A, Simon P, Pomar JL, Birnbaum DE, Greve HH, et al. Multicentered European study on the safety and effectiveness of the On- $\mathrm{X}^{\circledR}$ Prosthetic Heart Valve: intermediate follow-up. Ann Thorac Surg. 2007;83:40-6.

23. Williams MA, van Riet $S$. The On-X heart valve-mid-term results in a poorly anticoagulated population. J Heart Valve Dis. 2006;15:80-6.

24. Chambers JB, Pomar JL, Mestres CA, Palatianos GM. Clinical event rates with the On-X bileaflet mechanical heart valve: a multicenter experience with followup to 12 years. Thorac Cardiovasc Surg. 2013;145:420-4.

25. Ely JL, Emken MR, Accuntius JA, Wilde DS, Haubold AD, More RB, et al. Pure pyrolytic carbon: preparation and properties of a new material, On- $\mathrm{X}^{\circledR}$ carbon for mechanical heart valve prostheses. J Heart Valve Dis. 1998;7:626-32.

\section{Discussion}

Dr A. Peter Kappetein (Rotterdam, The Netherlands). The conflict of interest that I have to report is that I am a member of the steering committee of the RE-ALIGN (The Randomized, Phase II Study to Evaluate the Safety and Pharmacokinetics of Oral Dabigatran Etexilate in Patients After Heart Valve Replacement) trial, which tested dabigatran in patients with mechanical heart valves.

Dear Dr Puskas, thank you very much for your excellent presentation and thank you for sending the report in advance of this meeting. Treatment with oral anticoagulant drugs is effective in the prevention of TE but inevitably increases the risk of bleeding events. Although low-dose anticoagulation leads to more thromboembolic events, a dosage that is too high can lead to hemorrhage. Anticoagulation monitoring and adjustment of the dosage is therefore steering safely between Scylla and Charybdis.

The trial that you just presented is a noninferiority trial. The difficulty with this type of study design is choosing the right noninferiority margin, the so-called delta. Because no meaningful data are available comparing warfarin to placebo with prosthetic heart valves, there is no ability to construct additional noninferiority boundaries.

Your sample size estimation was based on a 1-sided proportion test with type 1 error of 0.05 and a power of $80 \%$ to test this noninferiority hypothesis with an absolute noninferiority margin of $1.5 \%$. The event rates on which you based your sample size calculation were not mentioned in the report; however, usually the TE rates will be as high as $3 \%$ to $4 \%$ annually among mechanical valve patients, and valve thrombosis can occur in $\leq 0.5 \%$ of mechanical valve patients annually. In contemporary practice, the risk of significant hemorrhage has been reported at $2 \%$ to $3 \%$. The number of patients in your trial was extremely low, only 375 divided into 2 arms. The comment and question that I have are the following.

When you lower the anticoagulation treatment, you will always lower the bleeding events, no doubt about this, although the valve thrombosis and thromboembolic events could increase. However, you cannot put 2 events in a composite endpoint of a noninferiority trial if they do not point in the same direction. It might well be that bleeding events will decrease more than thromboembolic events will increase. In this study, you mixed the efficacy endpoints with the safety endpoints.

During the past couple of years, new anticoagulant drugs have been tested against warfarin in patients with atrial fibrillation. The thromboembolic events were even greater than those in the patients with mechanical heart valves, and these studies more or less used the same noninferiority margin that you used in your study. However, these studies included many more patients: ARISTOTLE (Apixaban vs Warfarin in patients with Atrial Fibrillation), 18,000 patients; ROCKET (Rivaroxaban Once Daily Oral Direct Factor Xa Inhibition Compared With Vitamin K Antagonism for Prevention of Stroke and Embolism Trial in Atrial Fibrillation), 14,000 patients; and RELY (Randomized Evaluation of Long-Term Anticoagulation Therapy), 15,000 patients. You could have saved those companies a lot of money with your study design.

My question is, should we regard this trial as a pilot study and should we not base the sample size only on the efficacy endpoint, being thromboembolic events, and in that case, should we design a new trial and increase the sample size to around 8000 patients and try to find the money for the trial somewhere? Is it not potentially dangerous if we do not know what the increase is of valve thrombosis and follow your conclusions?

Then another question. Should a third arm of the new trial include one of the new anticoagulant drugs? What do you think is the reason that dabigatran worked in the patients with atrial fibrillation but did not work in the patients with mechanical heart valves?

Thank you very much.

Dr Puskas. Thank you, Pieter. I share your concern about a noninferiority design for our trial. It was certainly a topic of much discussion with the FDA 8 years ago when this trial was designed and approved by the FDA. As you commented, thrombotic events and hemorrhagic events were not moving in the same direction, and this is just as we would expect. I showed a slide that recapitulates old studies that showed that thrombotic events move in one direction and bleeding events in the other.

What we are really looking for is to determine a "sweet spot" where those 2 curves intersect. Although it is theoretically or intellectually correct to say that thrombosis is the efficacy issue and hemorrhage the safety issue, we were obliged to combine those, for 2 reasons. First, the practical reason, no company will sponsor an 8000-patient, randomized trial; and second, the clinical reason, this was in fact a tradeoff in the minds of the patients and clinicians. So, it is a relevant clinical endpoint, this unholy composite, if you will, of thrombosis and hemorrhage.

The factors that affect bleeding are probably valve independent for the most part. They relate to the patient and the anticoagulant administered. The factors that affect thromboembolism or thrombosis include the above and patient factors and factors related to the therapy administered; however, they also involve, importantly, 
the design elements of a valve. So, what the FDA is doing in this investigational device exemption is trying to study the valve and whether this particular valve has a different "sweet spot" in terms of the risk of bleeding and thrombosis relative to other valves.

Now, I do not work for the company; I have no financial relationship with the company. I am impressed by the design of the valve from an engineering point of view and from a materials point of view. The present study really was to determine whether that difference in design will move the TE curve along the bleeding curve such that the "sweet spot" would be lower and more attractive to patients and clinicians. I think that is an appropriate answer to your first question.

In terms of your second question, why did dabigatran not work; I am amazed it did not work. One of the elements of that trial was that double valves were allowed. It was sort of an "all-comers" type of trial. I wonder if that had been held strictly to isolated AVR or isolated mitral valve replacement, whether you might have had a different result. However, direct thrombin inhibitors are relatively new, and we do not understand them as well as we understand warfarin, which has been around for 40 years. Another possible explanation might relate to the relatively short half-life of dabigatran and that the dabigatran trial did not include aspirin administration. A patient in the dabigatran trial who skipped 1 or 2 doses of dabigatran with, for example, a double mechanical valve replacement, is immediately at high risk of a thrombotic event. In contrast, a patient who skips 1 dose of warfarin while also taking aspirin is probably at a lesser immediate risk of thromboembolic events. The increased hemorrhagic complications seen in the dabigatran trial might have been related to the rather high dose of the drug given in that trial. However, these explanations are speculative.

Dr Hartzell V. Schaff (Rochester, Minn). In one of the slides I think I saw that you had 6 reoperations in 1 group. What were those for?

Dr Puskas. Early reoperation for bleeding was the most common perioperative event, and those were typically before randomization.

Dr Michael A. Acker (Philadelphia, Pa). One of the key elements to your design was point of care testing at home for both groups. That is not universally done; in fact, I would say across the United States, that is unusual. Do you think these results would hold up, given a standard practice of managing it, because that type of tight control is probably not the real world.

Dr Puskas. It (point-of-care home INR testing) is not the real world in America now. It is the real world in Scandinavia and some other regions. So, I think your comment is absolutely well taken, Mike.

We found in careful analysis of the 53,000 INR endpoints that we have and correlating those with adverse events that the variability in INR is very important in affecting adverse events, both bleeding and clotting, and it seems to be more impactful than the actual mean INR. Whether you are in the test group, with an INR of 1.5 to 2, or in the control group, INR 2 to 3, it would seem to matter more whether you are good about doing your testing and controlling your INR in your range than which range you are in. Bleeding events can occur after a relatively brief period high outside the range; hemorrhagic events are particularly sensitive to (poor) INR control.

I think that we in America need to catch up with what should be considered the standard of care in other parts of the world. Home INR monitoring is available, it is not high tech, and it is much easier for patients. To be perfectly blunt, there is really no excuse for us not using it uniformly in America.

Dr Acker. There is a reimbursement issue, as you know.

Dr Puskas. It, quite frankly, is a conflict of interest for local care providers and their patients' well-being. A small revenue stream occurs to cardiology offices and primary care doctors running warfarin clinics, and that is keeping us in the system that we have now rather than home INR monitoring through larger, centralized warfarin clinics. The coordination of home INR monitoring and clinical care in the present trial is far better than what I have provided to my own patients in the past. However, with the knowledge we have gained from the PROACT trial, we are strongly encouraging home INR monitoring for all patients who are treated with warfarin.

Dr Mohamed Emara (Cairo, Egypt). Did you face the problem that you cannot reach even this target of low INR with a large dose of warfarin, and what type of warfarin do you use, hydrophobic or hydrophilic? We have this problem in Egypt. Sometimes, we reach to $11 \mathrm{mg}$ and we do not reach $>1.2$. What is your comment about that?

Dr Puskas. There are a small number of patients who are relatively warfarin resistant and require large doses, but we have not had to exclude anybody from the trial because of an inability to anticoagulate them. The patients were encouraged to use brand name warfarin, but not all did, and generic warfarin was used by some patients. Thus, I cannot tell you that everybody received exactly the same kind of warfarin. That was not feasible. 
APPENDIX E1. Investigator list

Institution

Emory University, Atlanta, Ga

Tacoma General Hospital, Tacoma, Wash

St. Francis Heart Center, Indianapolis, Ind

Maine Medical Center, Portland, Maine

Southern Arizona Veterans Affairs Medical Center, Tucson, Ariz

Sentara Norfolk General Hospital, Norfolk, Va

St. Joseph Mercy Hospital, Ypsilanti, Mich

Duke University Medical Center, Durham, NC

University of Arizona, Tucson, Ariz

University of Texas Southwestern Medical Center, Dallas, Tex

University of Florida, Gainesville, Fla

Florida Hospital, Orlando, Fla

VA Medical Center, Oklahoma City, Okla

St Paul's Hospital, Vancouver, British Columbia, Canada

Providence Heart and Vascular Institute, Portland, Ore

Loma Linda University Medical Center, Loma Linda, Calif

Rex Cardiothoracic Surgery, Raleigh, NC

Forsyth Medical Center, Winston-Salem, NC

New Mexico Heart Institute, Albuquerque, NM

Mary Washington Hospital, Fredericksburg, Va

Beth Israel Deaconess Medical Center, Boston, Mass

Baylor Research Institute, Dallas, Tex

St Luke's Roosevelt, New York City, NY

Texas Cardiac Center, Lubbock, Tex

Cotton O'Neil Clinical Research Center, Topeka, Kan

Ohio State University, Columbus, Ohio

Washington University, St Louis, Mo

Cleveland Clinic, Cleveland, Ohio

Cardiac Surgical Associates, Kissimmee, Fla

Texas Heart Institute, Houston, Tex

Johns Hopkins University, Baltimore, Md

Christiana Hospital, Newark, Del

St Luke's Hospital, Kansas City, Mo
Principal investigator

John Puskas, MD

Dennis Nichols, MD

Allen Graeve, MD

Charles Anderson, MD

Marc Gerdisch, MD

Reed Quinn, MD

Lilibeth Fermin, MD

Birger Rhenman, MD

Michael McGrath, MD

Bobby Kong, MD

G. Chad Hughes, MD

Gulshan Sethi, MD

Michael Wait, MD

Tomas Martin, MD

Kevin Accola, MD

Timothy Trotter, MD

Jian Ye, MD

E. Charles Douville, MD

Alfredo Razi, MD

Lance Landvater, MD

David Duncan, MD

Paul Levy, MD

Jeffrey Askew, MD

Robert Hagberg, MD

Barron Hamman, MD

Daniel Swistel, MD

M. Fawaz Shoukfeh, MD

Peter Tutuska, MD

C. B. Sai-Sudhakar, MD

Ralph Damiano, MD

Gosta Pettersson, MD

Matthew Campbell, MD

Igor Gregoric, MD

Duke Cameron, MD

Ray Blackwell, MD

Keith Allen, MD 


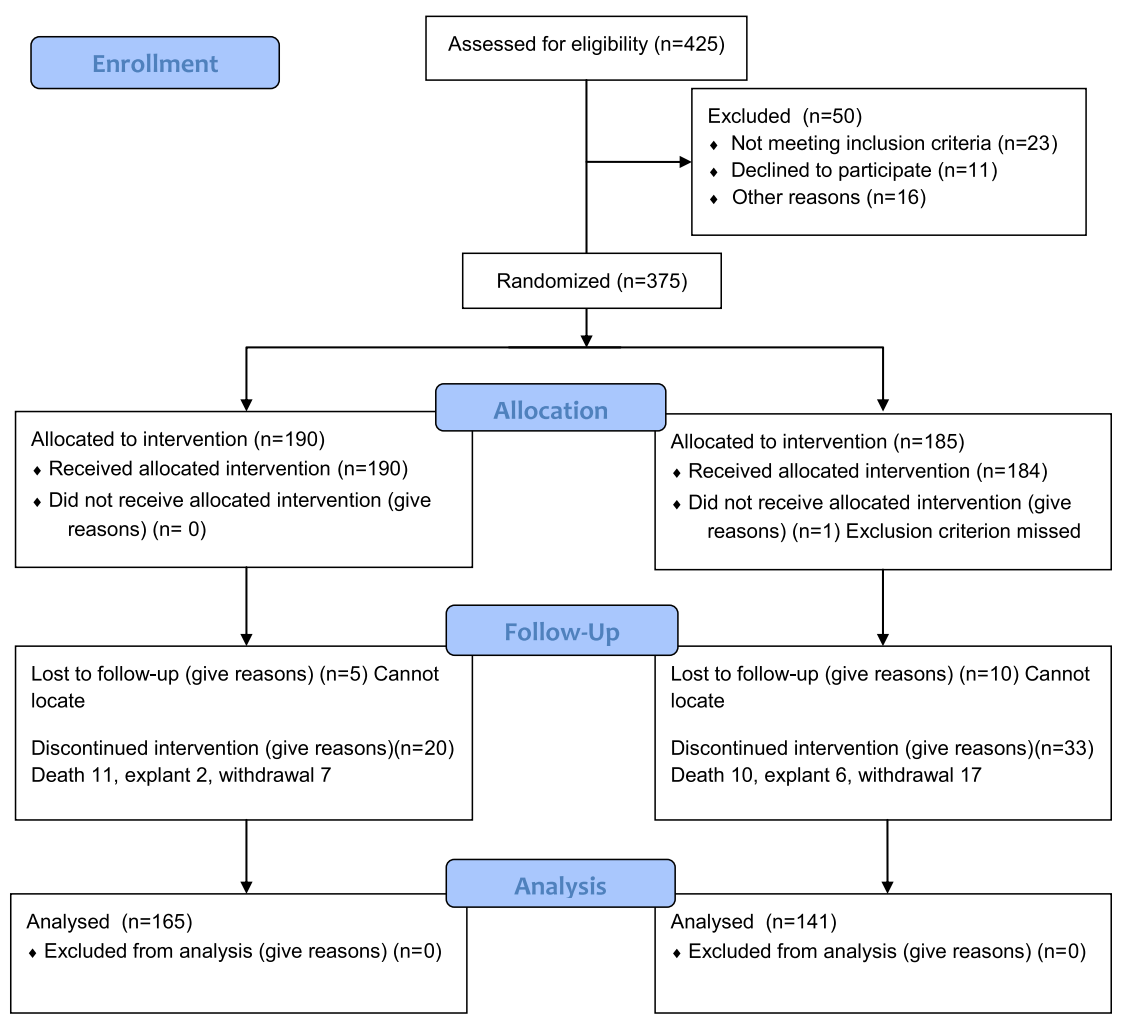

APPENDIX E2. Consolidated Standards of Reporting Trials (CONSORT) 2010 flow diagram. Reprinted, with permission, from Schulz KF, Altman DG, Moher D, for the CONSORT Group. CONSORT 2010 statement: updated guidelines for reporting parallel group randomised trials. Ann Intern Med. 2010;152:726-32. 